\title{
Hematocolpos secondary to imperforate hymen
}

\author{
Brian T. Kloss • Nicholas E. Nacca • Richard M. Cantor
}

Received: 26 January 2010 / Accepted: 10 February 2010/Published online: 6 May 2010

(C) Springer-Verlag London Ltd 2010

A previously healthy 12-year-old female was sent to the Emergency Department by her pediatrician for workup of severe suprapubic abdominal pain radiating to her lower back. She reported having waxing and waning pain for 1 month that had awoken her from sleep the previous evening. The patient denied nausea, vomiting, and diarrhea, but reported mild urinary retention. Per history she was premenarchal.

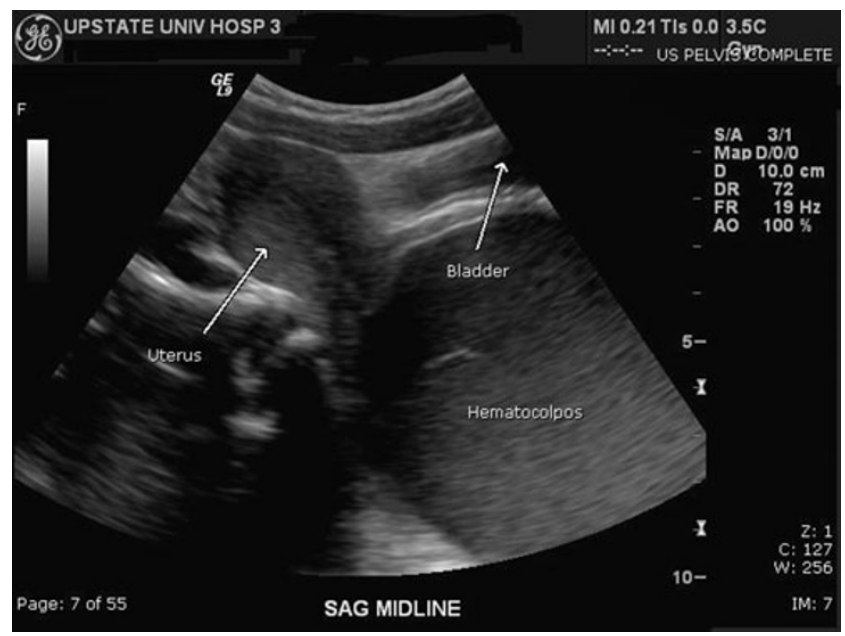

Fig. 1 Sagittal US view

\footnotetext{
B. T. Kloss $(\bowtie) \cdot$ N. E. Nacca $\cdot$ R. M. Cantor

Department of Emergency Medicine,

State University of New York, Upstate Medical University,

750 East Adams St,

Syracuse, NY 13210, USA

e-mail: klossb@upstate.edu

N. E. Nacca

e-mail: naccan@upstate.edu

R. M. Cantor

e-mail: cantorr@upstate.edu
}

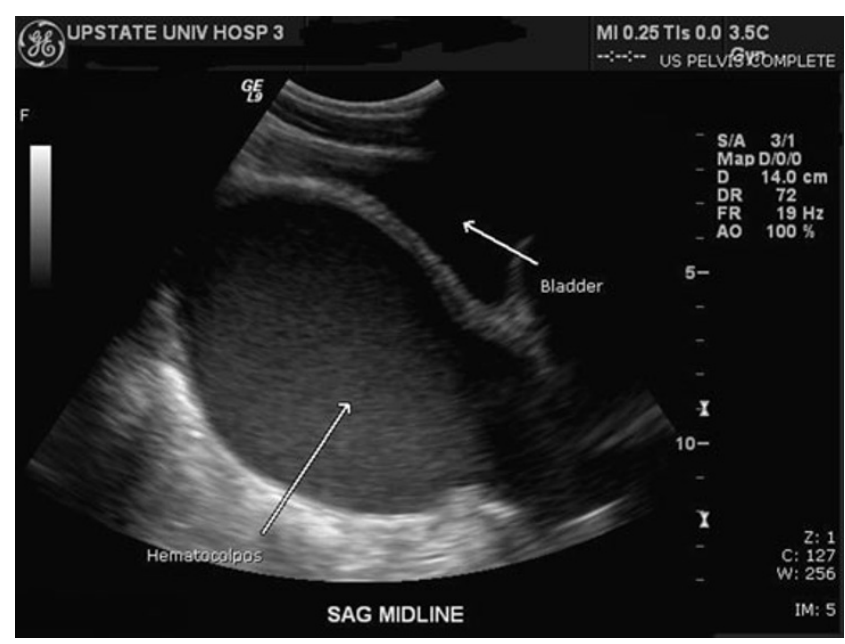

Fig. 2 Sagittal US view

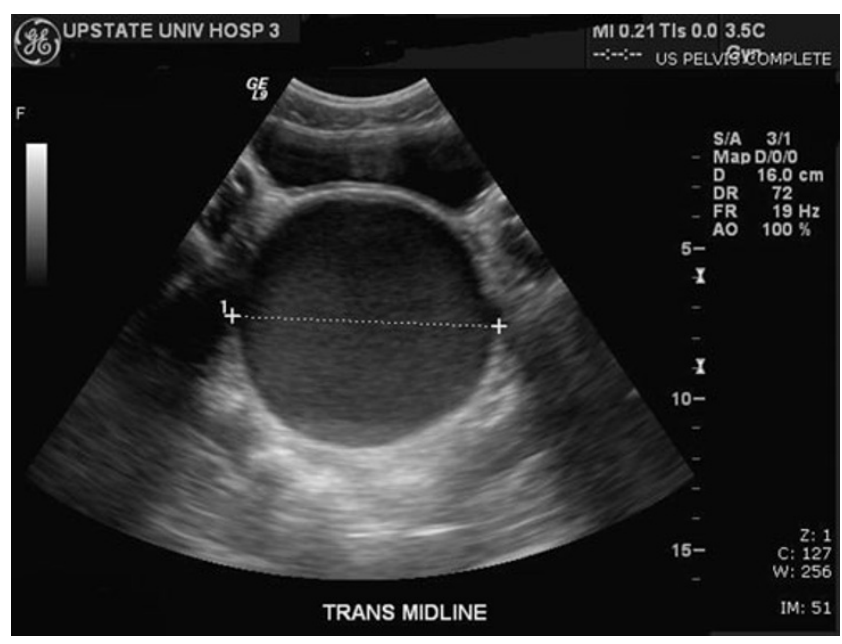

Fig. 3 Transverse US view 
Her vital signs were heart rate (HR), 83; blood pressure, 129/ $85 \mathrm{mmHg}$; temperature, $36.1^{\circ} \mathrm{C}$. Physical exam revealed a healthy adolescent female with signs of both thelarche and adrenarche. Her abdomen was soft and non-tender, but notable for a palpable pubic mass. All blood and urine laboratory tests, including $\beta$-HCG, were normal. Ultrasound examination revealed a $13.7 \times 8.0 \times 8.8-\mathrm{cm}$ complex fluid-filled structure extending inferiorly from the uterus, obscuring visualization of the cervicovaginal junction. A genitourinary exam revealed an imperforate hymen. A diagnosis of hematocolpos secondary to imperforate hymen was made and surgically confirmed.

Imperforate hymen occurs in approximately 1 in 1,000 females [1], and found incidentally on physical exam $(43 \%)$, it is treatable and does not cause significant morbidity [2]. If not screened for and treated early, patients present at menarche with a history of cyclical pelvic or abdominal pain and urinary retention due to hematocolpos. Physical exam findings may include a palpable abdominal mass and an intact bulging blue hymen [3, 4]. Potential complications of delayed diagnosis include retrograde menstruation and rarely ruptured hematosalpynx [5]. Diagnosis is supported by history, physical exam, and ultrasound findings, and should prompt immediate consultation with a gynecologist [3] (Figs. 1, 2 and 3).

\section{References}

1. Parazzini FF (1990) The frequency of imperforate hymen in Northern Italy. Int J Epidemiol 19(3):763, Print

2. Posner JC, Spandorfer PR (2005) Early detection of imperforate hymen prevents morbidity from delays in diagnosis. Pediatrics 115 (4):1008-1012, Print

3. Basaran M, Usal D, Aydemir C (2009) Hymen sparing surgery for imperforate hymen: case reports and review of literature. J Pediatr Adolesc Gynecol 22(4):E61-E64, ScienceDirect. Web. 20 Jan. 2010

4. Dane C, Dane B, Erginbas M, Cetin A (2007) Imperforate hymen-a rare cause of abdominal pain: two cases and review of the literature. $\mathrm{J}$ Pediatr Adolesc Gynecol 20(4):245-247, ScienceDirect. Web. 20 Jan. 2010

5. Bakos O, Berglund L (1999) Imperforate hymen and ruptured hematosalpinx: a case report with a review of the literature. J Adolesc Health 24(3):226-228, ScienceDirect. Web. 20 Jan. 2010 